\title{
ORGANISATIONAL CULTURE: A CONTEMPORARY MANAGEMENT PERSPECTIVE
}

\author{
Richard Weeks: Department of Information Science, University of Pretoria.
}

\begin{abstract}
Purpose: The purpose of this paper is to analyse the concept "organisational culture from a traditional and a more contemporary
\end{abstract} management perspective.

Problem investigated: The concept organizational culture has assumed a very prominent place within the management literature and has been analysed from diverse multidisciplinary perspectives. Central to the importance attributed to the concept is the fact that it acts as a perceptual and behavioural determinant, which implies that it will have a significant impact on all human related institutional activities and thus the interest in the concept and its management. Researchers and management practitioners have come to assume that while the concept is difficult to manage in practice, it is possible to determine the prevailing culture of an institution, identify what is termed to be a desired culture for an institution and then analyse the cultural gap that exists. Based on the analysis conducted, it is further frequently assumed that the transition from the prevailing to a desired culture can be managed. $A$ more contemporary management perspective, based on complexity theory, would appear to challenge the assumption of being able to actively manage the organisation's culture transformation process to ensure that a desired culture is manifest within the institution. The traditional and more contemporary approaches for dealing with the concept "organisational culture" are the focus of discussion and analysis in this paper.

Methodology: A multidisciplinary literature review and analysis is undertaken to gain an insight of traditional and contemporary management theory and practice, as it relates to the concept "organisational culture" and its management.

Findings: An important conclusion drawn from the study is that traditional paradigms of organisational culture management, that evolved within a more mechanistic manufacturing economy, is no longer effective for dealing with the unpredictable and disruptive changes of a highly complex, competitive and turbulent global services economy. It is suggested that a more contemporary complexity theory approach in dealing with the concept may in fact be more appropriate.

Value of the research: Increasingly executives and managers are confronted with the complex realities associated with managing a modern day enterprise in a very turbulent and emerging global services economy. The concept organisational culture, as a perceptual and behavioural determinant, will have a multifaceted influence in the management of the enterprise and the insights derived from this research study could assist executives and managers in dealing with organisational culture as an emergent property, as opposed to a purposefully managed entity.

Conclusion: A primary conclusion drawn from the study is that within a contemporary management setting the notion of organisational culture as an emergent, as opposed to actively managed, concept would appear to be more realistic. This would imply that executives and managers at best can attempt to influence its emergence and consequently its impact as a perceptual and behavioural determinant.

Key words and phrases: Organisational culture, economic meltdown, the services economy, complexity theory, and servitization. 


\section{INTRODUCTION}

"When we understand culture as the meaning giving system of a society then it becomes a current ever evolving force which can best be experienced in active engagement with today's human beings as well as with local nature, not with yesterday's historical beings"

Ronnie Lessem and Alexander Schieffer, 2009:118

Attested to in the introductory quotation is the emergent nature of an institution or societal culture as a living system that is responsive to a forever changing and complex contextual setting. Implied is the notion of a complex adaptive systems (CAS) perspective in dealing with the concept "organisational culture". This would seem to stand in contrast to a more traditional organisational culture perspective of engendering a sense of order and stability that is captured in defining the concept as "the way things are done around here" (Deal \& Kennedy, 1982:4; Hawkins 1997:419; Tromp, 1998:32; Trompenaars and Prud'Homme, 2004:14-15; Weeks \& Lessing, 1993:119). In adopting a more traditional perspective of the concept, Munck (2002:23) suggests that transforming an organisation's culture constitutes one of the most fundamental, challenges confronting an institution, as people's natural inclination is to hold on to whatever feels familiar, even if confronted with better alternatives. The two views of the concept "culture" as an enduring force and a natural evolving living system, appear to not only stand in stark contrast to each other, but it is argued influence the way executives and managers deal with the concept in practice.

The more traditional view is one of being able to actively and intentionally manage the concept to realise a desired or envisioned culture, although it is also acknowledged that in practice it is extremely difficult to achieve (Brown 1995:130; Jaskyte, 2004:154,156; McCormick, 2008:79-83; Trompenaars and Prud'Homme, 2004:171). It would seem that management practitioners have bought into the idea that culture can be managed and as noted by Trompenaars and Prud'Homme's (2004:34) institutions have as a consequence spent significant financial resources on consultants brought in to assist them to "roll-out" a new desired culture. This would seem to be contradicted by a more contemporary complexity theory approach in dealing with the concept, where it is suggested that it is a naturally evolving "living system" and the outcome of the culture formation process can therefore not be predicted with any degree of certainty (Bate, 1994:136; Bennet \& Bennet, 2004:15). McCormick (2008:78) tends to substantiate this view in claiming that "culture for the most part develops in an evolutionary unmanaged process". Hawkins (1997:434), citing Nodoushani, articulates a postmodernist view of culture, namely as not constituting a strong unitary meta-narrative, but of celebrating ambiguities and a multiplicity of conflicting views. In a very similar sense Snowden (2002:4) suggests that if cultural interventions are seen as pattern revealing and influencing activities institutions will have a far greater degree of success in dealing therewith.

Organisations as living networks of human interaction and activity, implies a need for a social systems construct in dealing with the concept culture. Trompenaars and Prud'Homme's (2004:34) suggests that if one where to understand culture as a meaning giving system of society, then it becomes a current and for ever evolving force, which can best be experienced in active engagement. Bennet and Bennet (2004:150) very specifically assert that culture emerges out of the nonlinear interactions that takes place among individuals and cannot be traced back to a single cause or individual. The researchers stress that emergence is not random, but rather the result of multiple interactions that settle down to internal coherence and patterns. 
Insinuated therefore in a sense is the management of patterns, in dealing with organisational culture as a CAS (Bennet and Bennet, 2004:151). While there is certainly no guarantee that a desired culture will surface from the interactions, it is deemed possible to implement interventions that may lead to desirable behaviour patterns and consequently a desired underpinning organizational culture (Bennet and Bennet, 2004:151). Snowden (2002a:2) also very pertinent argues that one cannot engineer a desired culture, as it constitutes a patterning of human interactions, which is not susceptible to design principles. Central to engineering systems thinking, that has become entrenched in traditional management thinking, is the notion of design, production, use and phasing out or disposal (Blanchard \& Fabrycky, 1998:19). It is a mental paradigm that has become so generally accepted that it has shaped culture management thinking as well and many unsuccessful attempts to design a desired culture may be attributed thereto.

The objective in this paper is to conduct an analysis of the two conflicting culture paradigms of management, namely a traditional Cartesian-Newtonian and CAS approach. This is undertaken by means of a multidisciplinary literature study, so as to gain and understanding of the concept and its management. In so doing note is in particular taken of the nature of the contemporary business environment in which institutions function. The emergence of a highly competitive global services economy, as well as the turbulent nature thereof, is for instance specifically taken into consideration. With this in mind, the point of departure in this paper is therefore one of undertaking a brief analysis of the contemporary business environment and the organisational culture implication associated therewith. The concept "paradigms", as a mental construct, and the institutional management implication thereof, with reference to organisational culture as a paradigm of management, is then briefly addressed. Thereafter a traditional and post-modern CAS perspective of the concept "organisational culture and its management are undertaken. In the final instance a summary of the key insights and conclusions derived from the research study is provided.

\section{AN ANALYSIS OF THE GLOBAL BUSINESS ENVIRONMENT AND ITS IMPACT ON CONTEMPORARY BUSINESS INSTITUTIONS}

"May you live in interesting times" is apparently purported to be an ancient Chinese curse (BBC, 2002; Dudley, 2007). If so it could be assumed that all modern day enterprises are living under this curse, as the world has truly become extremely turbulent and subject to unforeseen and unexpected events that have had a very dramatic impact on institutions and society. Business institutions it would appear are experiencing ever increasing difficulty in realigning their management response to a world of discontinuous change or as termed by Arensman and Jurcy (2006:13) "moments of truth", defined as reflecting turning points in organisational and people's lives. A typical such moment could be deemed to be the prevailing economic meltdown which has left few people and organisations untouched. Another such turning point that has been less dramatic in its emergence, but that is having a profound effect on business and industry, is the growth of the services economy (Chesbrough \& Spohrer, 2006:36; Wölfl, 2005:6).

The Royal Society (2009:v) attests to the fact that the link between science and the manufacturing world is now taken for granted, but between half and three-quarters of all wealth world-wide is now created through services that are rendered to clients. It is a moment of truth that requires a very different way of looking at and responding to a global services economy, from an organisational management perspective and it is suggested by Arensman and Jurcy (2006:13) that it is one that necessitates the creation of a services culture. IfM and IBM (2008:1) confirm that "services form a growing proportion of the world economy and are becoming central to the way businesses, governments, families and individuals work". It is important to note in this regard that service systems are defined as "dynamic configurations of people, technologies, organisations and shared information that create and deliver value to customers, providers and other stakeholders. (IfM \& IBM, 2008:1). Clearly articulated in this definition is the notion of services as a complex system. It is in fact claimed in the IfM and IBM (2008:1) report that the scale, complexity and interdependence of today's service systems have been driven to an unprecedented level, due to globalisation, demographic changes and technology developments. 
The manufacturing industry, according to Gebauer \& Fleisch (2007:337), has undergone something of a service revolution. Fitzsimmons and Fitzsimmons (2008:3) similarly contend that the world is witnessing the greatest labour migration since the industrial revolution, namely one from agriculture and manufacturing to services. The Royal Society for instance found that agriculture now only accounts for $1.5 \%$ of all employment in the United Kingdom, with manufacturing representing $10 \%$ and services a very significant $80 \%$. Of even more relevance is their finding that $82 \%$ of graduates entering full time employment were destined to enter the services sector (The Royal Society, 2009:x).

An analysis of the World Economic Forum's (2009:55) competitiveness report for 2009-2010 reveals that just over $70 \%$ of the countries listed derive the majority of their gross domestic product (GDP) from the services sector, which would seem to confirm Fitzsimmons and Fitzsimmons's (2008:3) contention of a labour migration. In the case of South Africa the World Economic Forum (2009:55) indicates that services account for $66 \%$ of the country's GDP, which quite clearly is very significant for a developing nation. The key point to note here is that the move towards a services dominant global and national economy inherently implies a change in the way business is conducted and consequently the culture of institutions. Research undertaken by The Royal Society (2009:v) lead them to conclude "that services are very likely to remain central to the new economy, not least because we are at or near a tipping point" and consequently "innovations now underway seem likely to change dramatically the way we live and to generate many services (though few can be predicted in detail at present)". This conclusion would seem to confirm a change in what was previously termed to be "the way things are done around here", which by definition therefore implies a need for culture change. The ability to take account of what The Royal Society (2009:x) terms to be the "human dimensions" in complex services systems therefore, undoubtedly, needs to be taken into consideration, particularly if seen within the light of the emergence of a services dominant global economy.

A primary purpose in accentuating the transition from a manufacturing to a service driven global economy, is the very fundamental differences associated with manufactured products and services. It is suggested that these differences imply a need for a very different paradigm of management to that that has traditionally evolved during a predominantly manufacturing era. It is suggested that the theoretical foundations associated with a services economy are multi-disciplinary and complex in nature. The IfM and IBM (2009:7) white paper for instance claims that "challenges facing modern organisations are, to a large extent, due to our poor understanding of the nature and behaviour of service systems" and it is therefore argued that "the vision of Service Science, therefore, is to discover the underlying principles of complex service systems". Strongly advocated in the paper is the need to "develop an interdisciplinary and intercultural approach to service research", in view of the complex nature and wide ranging management challenges associated with services science (IfM and IBM, 2009:1). A case in point being the challenges associated with moving from a transaction (product) to a relationship (services) based business model. Brax (2005:152) specifically claims that "the implicit transaction-oriented business philosophy of the manufacturer does not support service offerings". The researcher insists that "services cannot be merely added on top of the original goodsdominated total offering, but a more radical approach is necessary to question the implicit view of the world in which the company operates" (Brax, 2005:152).

Notably, in developing a service orientated business model Osterwalder (2004:338) explicitly accentuates "customer relations development" as a distinctive component and defining characteristic of the model. Following a similar trend of thought, Edvardsson, Holmlund and Strandvik (2008:339) conclude that manufacturing companies in adopting a services based logic will increasingly need to incorporate a services philosophy or concepts as the basis for their business. It seems to also be a trend that is also reflected in Gebauer and Fleisch's (2007:337) contention that services require a radical approach, namely a change in existing company structures and activities, and certainly a change in underlying behaviour patterns. 


\section{ORGANISATIONAL CULTURE: A CONTEMPORARY MANAGEMENT PERSPECTIVE}

The picture that starts to emerge from the literature study is one of a very fundamental transformation taking place in the global economy, with the emergence of services as the dominant economic sector. While having a direct impact on institutions at an operational level, it would also appear to have far ranging consequences in terms the underpinning philosophy and management paradigms associated with the transformation from a transactional to a relationship orientated business model. It is therefore concerning to note that, Gebauer and Fleisch (2007:337) explicitly state that the existing literature largely avoids the issue of having to deal with complex behavioural patterns, as a dimension of transformation management.

The relative instability of the services dominant economic era, also appears to have engendered a more complex services systems orientation, as reflected by the subprime economic meltdown, which in reality has its origins in the financial services and not the manufacturing sector of the economy. An inherent characteristic of such a complex business environment is the difficulty experienced in predicting the future with any degree of certainly. A very fundamental assumption underpinning traditional management paradigms is the ability to determine a future worldview and develop strategic and operational plans to position an enterprise within this envisaged future (Mintzberg, 1994:8; Weeks \& Lessing 1993:37). It is an intentional strategic approach that results in a deliberate strategy, one which stands in stark contrast to the notion of emergent strategy that evolves in response to changing and largely unforeseen contextual conditions (Mintzberg, 1994:24). Quite pertinently Mintzberg (1993:25) states that the literature generally assumes an intentional or deliberate strategic approach, to the virtual exclusion of emergent strategy. Citing Peter Drucker, Lessem and Schieffer (2009:5) contend that every so often in Western history there occurs a sharp transformation, during which society - its world view, basic values, social and political structures and its institutions - rearranges itself. The researchers go on to suggest that the world is currently living through such realignment (Lessem and Schieffer, 2009:5). Apparently stemming from such realignment is a new world hypothesis of "how the world works", which is itself woven around a root metaphor (Lessem and Schieffer, 2009:5). The traditional metaphor of the manufacturing era it could be argued is vested in the Cartesian-Newtonian paradigm that has dominated Western society for several hundred years according to Kilmann (2001:xv). It is referred to by Lessem and Schieffer (2009:5) as the rise of the machine or mechanistic methophor. A more appropriate metaphor for a very turbulent contemporary socio-cultural and global socio-economic context would appear to be that of a complex adaptive system.

Insinuated in the discussion is the notion of context acting as a determinant for appropriate management thinking and behaviour. Snowden (2005:2), in this regard, very pertinently suggests that culture constitutes the patterning or our interactions with our environment and it is therefore not susceptible to intentional design principles. Axelrod and Cohen (1999:xvi) also assert that "contextual forces determine interaction patterns". Each context therefore engenders sets of cultural attributes, such as values, beliefs, assumptions, philosophies, expectation, norms and traditions, that in turn act as perceptual and behavioural determinants that direct appropriate interaction patterns for a particular contextual setting (Weeks \& Lessing, 1993:29). Smit and Cronje (2004) it would seem concur that organisational culture embodies a system of shared values, beliefs and convictions about the world and how it works. Adopting a similar social interaction orientation, Schermerhorn, Hunt and Osborn (2008:37) define culture as the learned, shared ways of doing things in a particular society, thereby attributing a social context connotation to the concept. It would therefore appear from the discussion that organisational culture, as a behavioural determinant, has a very strong contextual connotation. So for instance a scientific management paradigm underpins the mechanistic metaphor and has become ingrained in traditional management thinking and it would appear that it certainly proved to be appropriate for a manufacturing era of reasonable contextual predictability. Axelrod and Cohen (1999:28) attest to the fact that "the industrial revolution made metaphors of machines and factory production widely available" and these mechanical conceptions infiltrated most of management thinking in the subsequent era of scientific management. The problem, however, is when traditional management paradigms fail to capture the realities associated with a contextual change and are consequently no longer able to inform appropriate behaviour. Then, as so clearly articulated by Kilmann (2001:xiv), "people and organizations become endangered". 
With the advent of the post-modern services or as often referred to as the knowledge economy, the world has become far more turbulent and subject to unforeseen and unexpected events and outcomes. The subprime initiated economic meltdown and the 9/11 terrorist attach on New York are typically such events that have left the world a fundamentally different place in their aftermath. The events themselves, once they have manifested themselves, such as global warming, have an immense impact on society and business institutions as well. Most of these events stem from a complex set of determinants that come together in a self-organising system to give rise to an emergent new reality. The traditional mechanistic paradigm of management is hardly appropriate for dealing with the turbulent and complex nature of such a contextual situation. The notion of innovation as a management response to a turbulent context is often reflected in the literature (Cropley, 2006:561; Ney,' Michna,' Ekmanis, Zeltins, \& Zebergs' 2008:43; Leskovar-Spacapan \& Bastic, 2007:533; Santos-Vijandea \& Âlvarez-Gonza'lez, 2007:514) and, as quite pertinently accentuated by Ishimatsu, Sugasawa, and Sakurai (2007:372), innovation needs to be seen as constituting a complex adaptive system. The importance attributed to innovation in a services dominant global economy is the role it plays in gaining a competitive advantage in a very competitive marketplace.

The preceding discussion brings to the fore the notion of two very different contextual conditions, namely a manufacturing and a services dominant global economy, characterised by a sense of stability and discontinuous change respectively. It is suggested that each of these contexts have engender the need for a particular paradigm of management, which in turn are based on a specific and different set of cultural attributes, manufacturing with a scientific management and services with a complex adaptive systems orientation. With this discussion serving as a source of reference, the concept paradigms of management and the culture connotation involved will be briefly explored in the following section.

\title{
PARADIGMS OF MANAGEMENT AND THE ASSOCIATED ORGANIZATIONAL CULTURE CONNOTATION
}

\begin{abstract}
"A paradigm is a coherent internally consistent approach for making sense of the universe and coping with life: essentially, how one sees, things, and behaves. Similar terms that are often used interchangeably with paradigm include archetype, gestalt, worldview, template, schema, mindset, mental model, and conceptual/theoretical framework"
\end{abstract}

Ralph H. Kilmann, 2001:17

Kilmann's (2001:17) introductory statement embodies many truths that have a very pertinent implication in analysing the linkage that exists with the concept organisational culture. In the first instance it is deemed to be an approach for sense making and coping with life. In a similar vein Seel (2000:2) views a paradigm as a self-consistent set of ideas and beliefs which act as a filter, influencing how we perceive and how we make sense of things. This is without doubt a very important conclusion as central to management thinking is the need to make sense of the business environment and its impact on the operations of an institution. The need to clearly understand and make sense of the business and competitive environment in fact captures a very fundamental aspect of many researchers approach to strategy formulation (Hough, Thompson, Strickland \& Gamble, 2008:11; Pearce and Robinson, 2007:11; Weeks \& Lessing 1993:35). The notion of paradigms acting as a perceptual and behaviour determinant also inherently implies an important association with the concept "organizational culture" (Seel, 2000:1; Tosti, 2007:21, Weeks, 2007:121). It is a linkage, which is far more pertinently reflected by Longo's (2002:208) contention that "in Kuhn's model, scientists are distinguished as a community because they share a worldview, assumptions, language, and a way of proving knowledge - what Kuhn terms a paradigm". The shared components frequently are reflected as constituting shared attributes in describing and defining the concept "organisational culture" (Bennet \& Bennet, 2004:150; Sanford \& Taylor 2006:145; Schermerhorn et al. 2008:11; Weeks \& Lessing, 1993:29; Weick \& Sutcliffe, 2007:112). Of further pertinence is the "mental" connotation attributed to the terms used interchangeably with 
that of the paradigm construct, by Kilmann (2001:17). It very pertinently alludes to the human attributes of thinking and sense making that is of paramount importance in managing an institution.

It is argued in this paper that institutions are not innate entities but webs of human social interaction, which give rise to emergent shared cultural attributes that in turn relate to a specific worldview or mental representation of contextual reality. It would appear that Capra (1997:6) comes to a very similar understanding in defining a paradigm as "a constellation of concepts, values, perceptions and practices shared by a community, which forms a particular vision of reality". Wikipedia (2010:1) confers on Thomas Kuhn the credit for being responsible for establishing the contemporary meaning associated with the term "paradigm", when he used the term to refer to "the set of practices that define a scientific discipline at any particular period of time". The term and the meaning attributed thereto it would seem have captured the attention of researchers not only within the scientific community, but has now also been attributed a more multidisciplinary connotation. It would also appear to not be all that out of line with Kuhn's (1970:11) own thinking, as may be noted when he asserts that "men whose research is based on shared paradigms are committed to the same rules and standards for scientific practice" and he goes on to claim that "the concept of a paradigm will often substitute for a variety of familiar notions". One such notion, it is suggested in this paper, correlates with the prefix "management" assigned to the concept, namely a shared management understanding or constellation of shared management concepts, values, perceptions and practices, as previously alluded to by Capra (1997:6). The key element here is the emphasis on a shared set of management related attributes that are also interwoven in the cultural fabric of the institution and that in turn gives meaning to the "way things are done around here". Quite pertinently Kuhn 91970:23) refers to a paradigm as an "accepted model or pattern" that would resonate with the connotation of the way that "things are done".

Seen from an organizational culture and management perspective there are two fundamental paradigms that dictate how "things may be done", a manufacturing transactional or services relationship orientation. The former is essentially founded on a scientific management and the latter on a CAS's paradigm. Kilmann (2001:13), views this as two dueling paradigms for making sense of a specific reality. In moving from a manufacturing to a services dominant context a different set of underpinning principles and cultural attributes come into play, which in essence define the predominant paradigm of management found to be most appropriate for making sense of the situation that exists. Kilmann (2001:14) argues that for most institutional transformation, fundamental change is not simply an exchange of one paradigm for another, but entails a shift from a dysfunctional worldview to one that is more effective for dealing with the contextual realities that exist. As the nature of reality changes, so the paradigm shown to be more effective in revealing of the "nature of things" needs to shift as well (Kuhn, 2001:25). The important point to be made is that the shift that takes place is not incremental adaptive in nature, but very fundamental and revolutionary in nature. The nature of the boundaries between complex (services) and ordered (manufacturing) states tend to be quite distinctive.

Cilliers (1998:3) identify the distinction made as being one between complicated and complex systems. The former can be taken apart and analyzed, while the latter are characterized as intricate sets of non-linear relationships that always cause distortions (Cilliers, 1998:3). Kurtz and Snowden (2003:462) similarly view the dynamics involved as one of making sense between a complex and complicated word. Snowden (2002b:105) makes use of a mechanistic metaphor for describing a complicated system, namely an aircraft as a system having thousands of components, all however knowable, definable and capable of being catalogued. The interaction between the parts can also be understood and analyzed. In contrast Snowden (2002b:462) makes use of a living system such as the human body to describe a complex system. In such a system, the components and their interactions are changing and can never be quite pinned down and the system, according to Snowden (2002b:105), is therefore in effect irreducible, which implies that cause and effect cannot be separated as they are intimately intertwined. Snowden (2002b:106) then makes the interesting observation that: "organisations tend to study past events to create predictive and prescriptive models for future decisions based on the assumption that they are dealing with a complicated system in 
which the components and associated relationships are capable of discovery and management". This is in line with the traditional mechanistic manufacturing paradigm of management, which assumes that cause effect relationships can be determined and consequential outcomes predicted. The nature of the complex domain is, however, one of the management of patterns, were one needs to identify the early signs of pattern formation and disrupt those deemed to be undesirable, while stabilising more favourable patterns (Snowden, 2002b:107).

The distinction between an incremental adaptive and a radical transformation of management paradigms, in moving from complicated to complex states, is also addressed by Kuhn (1970:84-85) who claims that the transition from a paradigm in crises to a new one from which a new normative science can emerge is far from a cumulative process, but rather constitutes a reconstruction of the field from new fundamentals. It is suggested by Kuhn (1970:85) that once the transition is complete the worldview of the profession will have changed completely. Inherently therefore insinuated by Kuhn (1970:92) is the notion that scientific revolutions are what he terms to be "non-cumulative developmental episodes" in which an older non functional paradigm is replaced with a new one deemed to be more in line with current reality.

Two opposing constructs of institutional reality emerge from the preceding discussion, namely ordered systems where cause effect can be determined and complex states where at best they can be retrospectively determined, but are ineffective for predicting the future. Each of these ordered and complex states are characterised by a set of fundamental underpinning principles, which determine an appropriate management paradigm, deemed to be the most appropriate for the context concerned. They also present different paradigms of culture management, which stand in stark contrast to each other. Namely, the notion that organisational culture can intentionally be managed on a basis of defined cause effect relationships versus culture as an emergent property that cannot be intentionally predetermined and engendered.

\section{A TRADITIONAL AND POST-MODERN CAS PERSPECTIVE OF THE CONCEPT "ORGANISATIONAL CULTURE” AND ITS MANAGEMENT}

Boje and Dennehy (2000) distinguish between a pre- modern, modern and post-modern context. The premodern context is deemed to reflect the agricultural or pre-industrial era (Boje \& Dennehy, 2000). The premodern era, according to Boje and Dennehy (2000), "was a period of artisans, craftsmanship, apprenticeship, and pride in the quality of one's workmanship", which culminated in the establishment of fraternities and sororities, rituals of initiation, rites of passage, and a tradition of Greek legends, shaping the pledges into active members (Boje \& Dennehy, 2000). The modern discourse is viewed by Boje and Dennehy (2000) as one of "progress, using technology of the machine and administrative bureaucracy to move man out of slavery, class-based and caste-based social structure into a gentler and more advanced society". Implied is the birth of the industrial era or as stated by Boje and Dennehy (2000), the era where "the modern organization combines the factory system of Taylorism, as exemplified by Henry Ford's assembly line with administration by rules and offices of Max Weber's bureaucracy". Jackson and Carter (1992:13) similarly view modernism as being characterized by the use of science. They claim that to date, management has essentially been a quintessentially modernist discipline and a major obstacle to the development of management knowledge has in effect been the albatross of scientific rationality, with management theory and practice both being widely influenced by "fashion and fad" (Jackson \& Carter, 1992:13-14).

Post-modern theory it is claimed by Boje and Dennehy (2000) makes inroads into status quo organization theory. It in effect constitutes the era of discontinuous change, where cause effect relationships break down. The emergence of postmodernism, Jackson and Carter (1992:16) suggest, is best understood at its most basic level as a loss of faith in the rational, in the unquestioned authority of objectivity, and in the efficacy of science. Ferris (2004) following a similar trend of thought, contends that in post-modern theory there is a conscious attempt to explore the diversity of experience of identifiable groups and to investigate issues from the perspective of each such group rather than to seek knowledge presented as "absolute". Cilliers 
(1998:112-113) concludes that a post-modernism approach is inherently sensitive to complexity and whether one is happy with the term or not, there is no denying that the world has become far more complex and it is a reality that society needs to confront if it is to survive. Complex systems are characterised by Cilliers (1998:119-122) as consisting of a large number of self-organising elements that interact dynamically in a non-linear manner, under conditions far from equilibrium, all of which would seem to imply a sense of unpredictability. Many contemporary events such as $9 / 11$, the economic meltdown, global warming and similar occurrences would seem to reflect the conditions associated with complex systems, thereby implying a postmodern connotation.

Boje and Dennehy (2000) cite Peter Drucker as suggesting that management went through paradigm shifts in moving from the pre-industrial, industrial, to the post-modern or what Drucker termed to be the "postbusiness" era (Boje \& Dennehy, 2000). The brief historical outline of the three eras in a sense correlates to the three economic sectors used in defining the modern day economy, namely the agriculture, manufacturing and services sectors of the global economy (World Economic Forum, 2008:55). Attributing a complex adaptive systems connotation to the services economy in a sense stems from the very nature of the services sector, namely the uncertainty associated with a large number of network interactions taking place, discontinuous innovative change, unpredictability of outcomes, small initial conditions leading to emergent conditions that have a major impact on society and institutions, the intangibility associated with services and the non-ownership characteristic thereof. These realities of a contemporary services management era clearly depict characteristics necessitating the need for adopting a CAS approach for dealing therewith.

Organizational culture within a modern or traditional manufacturing context assumes that a desired culture can be predetermined and intentionally managed to ensure that the institution's strategy and culture are in alignment. Hough et al. (2008:297) describe this approach as one where the organisation's vision provides a clear picture where the organisation is at present and where it would like to be, strategy providing the means to realise the vision and a culture strategy that defines the desired culture to be established for strategy implementation. It is pertinently stated by Hough et al. (2008:301) that "the organization's culture should support the overarching strategy". The purpose of developing a culture strategy is therefore directed at ensuring strategy and culture alignment. McCormick (2008:x) very pertinently stresses that "culture is, in reality, a critical foundation piece for any organization, and it is more than a theory- it is a manageable entity". Culture according to McCormick (2008:xi) can be architecturally designed by creating a set of core organisational values that define expected behaviours, which then serve as a frame of reference for hiring and developing staff. It follows that it is a management approach which assumes that cause effect relationships can be determined and outcomes consequently can intentionally be managed. James Martin $(1995: 455,461)$ is another researcher who views organizational culture as being able to adapt and undergo sudden quantum-change shifts. Martin (1995:455) claims that most mature corporations have the wrong culture for the present era, as it was set in place before the age of empowered teams and kaizen practices and therefore suggests the need for an "enterprise engineering" approach that pays specific attention to the need for culture realignment. The picture that emerges is one of an essentially manufacturing era where practices such as total quality management, enterprise reengineering, and Kaizen were the order of the day and culture was seen as being able to be realigned to support such practices. Consequently the management paradigms established during this predominantly manufacturing era become entrenched in what may now be termed to be traditional management theory and practice. It is therefore emphasised that traditional management and cultural paradigms need to be analysed and seen with the context in which they originated, namely one dominated by scientific thinking and practice.

The transition to a services dominant global economy, dealt with above, did certainly not go unnoticed by traditional manufacturing organizations and many embarked on a servitization process, namely one of moving from a transaction to a relationship focused strategic orientation. This by implication implies the need for having to address the culture considerations involved as well, something not always realised by the institutions concerned who attempted to add a services layer to an existing manufacturing operational 
infrastructure. The results were in some cases not quite what they expected. Not suggested is that the traditional cultural attributes associated with a manufacturing setting need to be discarded, as aspects thereof still assume relevance such as that associated with principles of total quality and project management. What is implied, however, is that a complex adaptive approach in dealing with culture change may be more appropriate. The CAS approach assumes that as part of the servitization process a new cultural realignment will emerge as well.

Vandermerwe \& Rada (1988:314) were the first researchers to have coined the term the term "servitization" with their statement that "modern corporations are increasingly offering fuller market packages or "bundles" of customer-focussed combinations of goods, services, support, self-service, and knowledge. But services are beginning to dominate. This movement is termed the 'servitization of business'". The researchers' paper drew attention to the emergent servitization trend detected and both academic and management interest in the phenomena gained in intensity. One of the early research findings it would seem was that services require organizational principles, structures and process that are relatively outside manufacturers' traditional frame of thinking, a factor already alluded to in this paper (Oliva \& Kallenberg 2003:161). In a very similar sense Weeks (2010:4) notes that the convergence of product manufacturing and services related processes or as termed to be servitization, inherently necessitates the need for a very fundamental change in traditional manufacturing paradigms, as services in terms of the very nature thereof introduce nuance differences that are not accommodated within a manufacturing operational setting. Of these paradigm changes, it is argued in this paper, the culture aspects involved are deemed to be not only very complex in nature, but also of vital significance as it can seriously jeopardise the servitization initiative.

A CAS approach in dealing with culture change assumes that while being of extreme pertinence to the servitization process it can not be intentionally managed to engineer a specific outcome. This is a point that has been well made in the preceding discussion. Munck (2002:23) essentially concurs with the argument that transforming an organisation's culture constitutes a very fundamental, challenge, as people naturally tend to hold on to whatever feels familiar, even if confronted with better alternatives. The researcher suggests that a possible solution may be one of getting people to truly want the change in the first place (Munck, 2002:29,30). Here a very important aspects come to the fore, that may not be all that readily apparent at first, namely inherent within the notion of a CAS approach to culture change is the aspect of wide spread staff involvement in the process. Fard, Rostamy \& Taghiloo (2009:46) would appear to be able to agree with this assessment, in adopting a social perspective of culture formation. The researchers suggest that "culture is constantly evolving and travels along an infinite continuum in a harmonious learning environment", one characterised by staff engaging in rituals, passing along corporate myths and stories, and using arcane jargon (Fard et al., 2009:46). Another researcher focusing on the sociological dimension of culture evolution is Weeks (2004:20) who notes that "people complain about their companies for the same reasons they complain about the weather-not because they hope to change anything but because these small rituals of negativity draw people together by affirming their shared experiences and their shared suffering ... the recitation of innocuous complaints becomes part of a comfortable routine that puts people at ease with one another, strengthen social bonds and builds a sense of community". Weeks (2004) further states that "as people internalize the culture, they learn not just how things are done around there but also how things are complained about".

In researching organisational culture using a "meme" perspective Weeks and Galunic (2003:1309) conclude that "firms are best thought of as cultures, as social distributions of modes of thought and forms of externalization". The researchers use the term "meme" to refer "collectively to cultural modes of thought (ideas, beliefs, assumptions, values, interpretative schema, and know-how), to describe culture as a social phenomenon, patterns of symbolic communication and behaviour that are produced as members of the group enact the memes they have acquired as part of the culture" (Weeks \& Galunic, 2003:1309). In essence therefore the researchers describe culture as a social phenomenon of patterns of symbolic communication and behaviour that emerge as members of the group enact the memes they have acquired as part of the 
culture (Weeks \& Galunic, 2003:1309). The theme that appears to materialise from this discourse is the unintentional organizational culture formation consequences that stem from the normal day-to-day social interaction patterns and organisational networking that surface within institutions. It is a theme that Bennet and Bennet (2004:150) would certainly seem to endorse, as may noted from their observation of culture as an emergent phenomenon, namely as "workers go about their daily business of communicating, solving problems, taking action, and reacting to information from others". It is further argued by the researchers that before an organisation can adopt new practices to significantly change the way it conducts its business, such as would be the case in servitization, it must be willing to admit that current practices are inadequate, which in essence requires a paradigm shift (Bennet \& Bennet 2004:11). It is a statement that resonates with Munck's $(2002: 29,30)$ preceding assertion that people need to truly want the change in the first place. Of pertinence therefore in the servitization discussion is the social interaction dynamics that takes place and the cultural implications thereof. The social connotation and its associated complexity, it is claimed by Brown (1995:5), are reflected in the politics of negotiation that takes place within institutions. The outcome of such negations, it is contended in this paper, is manifest in the cultural attributes that emerge and consequently shape the culture of the institution. To quote Bennet and Bennet (2004:151) in this regard, the emergence is not random but rather the result of interactions that settle down to internal coherence and patterns.

The complex adaptive system view of culture as emerging patterns implies that management would need to identify, as suggested by Snowden (2002b:107), those patterns deemed to favourable and those that will hinder the transition from a manufacturing operation to one inclusive of services related activities. The favourably patterns Snowden has noted need to be stabilised, while those hindering the process need to be disrupted (Snowden, 2002b:107). Each of these interventions can, however, give rise to new culturally determined emergent behavioural patterns that were not intended, as even small changes in initial conditions can have dramatic consequences as a result of the non-linear interactions that take place (Cilliers, 1998:4). Axelrod and Cohen (1999:8) also stress that when multiple populations of agents are adapting to each other (as would be the case in management initiated interventions) the result is a co-evolutionary process the outcome of which is uncertain. This notwithstanding, Axelrod and Cohen (1999:8), very pertinently state that "while complex systems may be hard to predict, they may also have a good deal of structure and permit improvement by thoughtful intervention". What adds to the complexity of these interventions is that most mental representations or mindsets are often deeply embedded below the surface of conscious thought (Pfeffer, 2005:125) and the interventions themselves can raise awareness and stimulate unexpected emotions that certainly complicate the culture transformation process. The translation of the narratives and stories accompanying the interactions that takes place, as a result of the culture interventions, can become misinterpreted giving rise to unintended and unexpected sets of new cultural determinants. In a sense therefore institutions become interpretation systems of participants who provide meaning for each other via their everyday interactions and negotiations (Browining \& Boudès 2005:32). Suggest therefore is a case of true intended meaning being lost in translation of narratives regarding perceived, as opposed to objective, reality of management intention. Pfeffer (2005:125) in fact advocates that in spite of the apparent complexity and difficulty involved, changing the way people think is still the most powerful means to ultimately change behaviour, which in terms of servitization is deemed to be of vital importance.

\section{Concluding summary and comments}

The literature study reveals that with the materialisation of services as the dominant sector of the global economy, manufacturing institutions are increasingly attempting to implement servitization strategies that require not only very significant systemic changes, but also a cultural realignment. Tradition paradigms of management that stem from the industrial era tend to suggest that an institution's culture can be intentionally managed so as to ensure a more appropriate strategy -culture alignment. The reality, however, would appear to be rather different if a CAS perspective is adopted in dealing with culture transformation. Culture then is deemed to be an emergent process, one where interventions intentionally implemented to transform the culture of the institution can give rise to unexpected, unintended and in some instances devastating 
consequences. It is suggested that in adopting a CAS approach the accent aught to be on pattern stimulating initiatives that need to be monitored to detect the emergent patterns and where relevant these aught to be either facilitated and reinforces or alternatively disrupted if not conducive to the transformation process. Space does not allow a more in depth analysis of culture transformation within a complex systems domain. The intention in this paper was, however, one of engendering an understanding as to the alternative traditional versus complex adaptive approach in dealing with culture transformation. As well as the intricacies associated with each of these cultural perspectives in implementing a servitization strategy.

It is suggested that has South African manufacturing institutions increasingly attempt to add services to the bundle of products made available to clients, they will be confronted with the dilemma of having to opt for a traditional or more contemporary approach to culture transformation. The insights gained from this paper could serve to assist the management of these institutions to take a more informed approach in dealing with the issue. At the core of the problem are entrenched paradigms of management that can significant lead to unexpected and unforeseen difficulties, this paper is an attempt at creating an awareness of these issues. 


\section{References}

Arensman R \& Jurcy J. 2006. Compete through service: Strategic handbook. Phoenix: Avnet

Axelrod R \& Cohen MD. 1999. Harnessing complexity: Organizational implications of a scientific frontier. London: Free Press.

Bate P. 1994. Strategies for cultural change. Oxford: Butterworth-Heinemann.

BBC. 2002. The Quote 'May You Live in Interesting Times'. Available online, http://www.bbc.co.uk/dna/h2g2/A807374 [6 February 2010]

Bennet A. \& Bennet D. 2004. Organizational survival in the new world: The intelligent complex adaptive system. Amsterdam: KMCl.

Blanchard BS. \& Fabrycky WJ. 1998. Systems engineering and analysis, $3^{\text {rd }}$ edition. New Jersey: PrenticeHall.

Boje D. \& Robert Dennehy R. 2000. Managing in the Postmodern World, $3^{\text {rd }}$ edition. Available online: http://business.nmsu.edu/ dboje/mpw.html [5 March 2008]

Brax S. 2005. A manufacturer becoming service provider: Challenges and a paradox. Managing Service Quality, 15(2):142-155.

Brown A. 1995. Organisational culture. London: Pitman.

Browining L. \& Boudès T. 2005. The use of narrative to understand and respond to complexity: A comparative analysis of the Cynefin and Weickian models. ECO, 7(3-4):32-39.

Capra F. 1997. The web o life: A new synthesis of mind and matter. London: Flamingo.

Chesbrough H. \& Spohrer J. 2006. A research manifesto for services science. Communication of the ACM, 49(7):35-40, July.

Cilliers P. 1998. Complexity and postmodernism: Understanding complex systems. London: Routledge.

Cropley DH. 2006. The role of creativity as a driver of innovation. Management of Innovation and Technology, 2006 IEEE International Conference, Singapore, China, 2:566 - 570.

Deal TE \& Kennedy AA. 1982. Corporate cultures: The rites and rituals of corporate life. London: Penguin.

Dudley WC. 2007. May you live in interesting times. Federal Reserve Bank of New York. Available online, http://www.newyorkfed.org/newsevents/speeches/2007/dud071017.html [14 February 2010]

Edvardsson B., Holmlund M. \& Strandvik T. 2008. Initiation of business relationships in service-dominant settings. Industrial Marketing Management 37(3):339-350

Fard HD., Rostamy AAA. \& Taghiloo H. 2009. How types of organisational cultures contribute in shaping learning organisations. Singapore management review, 31(1):49-61. 
Ferris T.L.J. 2004. The interplay of modernism, postmodernism and systems engineering. Paper presented at IEEE International Engineering Management Conference: Innovation and entrepreneurship for sustainable development, 18-21 October, Pan Pacific Hotel, Singapore.

Gebauer H. \& Fleisch E. 2007. An investigation of the relationship between behavioral processes, motivation, investments in the service business and service revenue. Industrial Marketing Management, 36(3):337 - 348

Hawkins P. 1997. Organizational culture: Sailing between evangelism and complexity. Human Relations, 50(4):417-439.

Hough J., Thompson AA., Strickland AJ. \& Gamble JE. 2008. Crafting and executing strategy: South African edition: Text, readings and cases. Berkshire: McGraw-Hill.

Ishimatsu, H., Sugasawa, Y. and Sakurai K. 2004. Understanding innovation as a complex adaptive system: Case studies from Shimadzu and NEC. Pacific Economic Review, 9(4):371-376, December.

Jackson N. and Carter P. 1992 Postmodern Management: Past-Perfect or Future-Imperfect? International Studies of Management. \& Organization, 22(3):11-26.

Jaskyte K. 2004. Transformational leadership, organizational culture, and innovativeness in nonprofit organizations. Nonprofit Management \& Leadership, 15(2):153-167, Winter.

Kuhn T.1970. The structure of scientific revolutions, $2^{\text {nd }}$ edition. Chicago: University Press.

Kurtz CF. \& Snowden DJ. 2003. The new dynamics of strategy: Sense-making in a complex and complicated world IBM Systems Journal, 42(3):462-483.

Leskovar-Spacapan G. \& Bastic M. 2007. Differences in organizations' innovation capability in transition economy: Internal aspect of the organizations' strategic orientation. Technovation, 27: 533-546

Lessem R. \& Schieffer A. 2009. Transformation management: Towards the integral enterprise. Burlington: Gower.

Longo B. 2002. What are paradigms and why do they shift? Professional Communication Conference 2002, proceedings IEEE International.

Martin J. 1995. The great transition: using the seven disciplines of enterprise engineering to align people, technology and strategy. New York: Amacom.

McCormick BA. 2008. Whats responsible for business success or failure? Its ... the organization's culture. Amherst: HRD.

Mintzberg H. 1994. The rise and fall of strategic planning: reconceiving roles for planning, plans, planners. Toronto: FP.

Munck B. 2002. Changing a culture of face time. In Harvard Business Review on culture and change. Boston: Harvard, p21-36.

Ney R., Michna J., Ekmanis J., Zeltins N. \& Zebergs V. 2008. Energy use and related risk management problems in CEE countries. Latvian Journal of Physics and Technical Sciences, 45(1):41-51. 
Oliva R. \& Kallenberg R. 2003. Managing the transition from products to services. International Journal of Service Industry Management, 14(2):160-172.

Osterwalder A. 2004. Understanding ICT-based business models in developing countries. International Journal Information Technology and Management, 3(2/3/4):333-348.

Pearce JA. \& Robinson RB. 2007. Strategic management: Formulation, implementation and control, $10^{\text {th }}$ edition, Boston: McGraw-Hill.

Pfeffer J. 2005. Changing mental models: HR's most important task. Human resources management, 44(2):123-128, summer.

Sanford LS. \& Taylor D. 2006. Let go to grow. Cape Town: Prentice Hall.

Santos-Vijandea ML. \& Âlvarez-Gonza'lez LI. 2007. Innovativeness and organizational innovation in total quality oriented firms: The moderating role of market turbulence. Technovation, 27:514-532

Schermerhorn JR., Hunt JG. \& Osborn RN. 2008. Organizational behaviour, $10^{\text {th }}$ edition. New York: John Wiley.

Seel R. 2000. Culture and complexity: new insights on organisational change. Organisations \& People, 7(2):2-9. Available online: http://www.new-paradigm.co.uk/culture-complex.htm

[5 February 2010]

Smit PJ \& Cronje GJ. 2004. Management principles: A contemporary addition for Africa. Johannesburg: Juta.

Snowden D. 2002a. Being efficient does not always mean being effective: A new perspective on cultural issues in organisations. Available online: http://www.cognitive-edge.org/ [6 November 2009]

Snowden D. 2002b. Complex acts of knowing: paradox and descriptive self-awareness. Journal of Knowledge Management, 6 (2):100-111

Snowden D. 2005. Being efficient does not always mean being effective: A new perspective on cultural issues in organisations. Available online: http://www.cynefin.net [6 August 2007]

The Royal Society. 2009. Hidden wealth: the contribution of science to service sector innovation. Royal Society, policy document 09/09, July 2009, Available online: http://royalsociety.org/Hidden-wealth-Thecontribution-of-science-to-service-sector-innovation//5 January 2010]

Tosti DT. 2007. Aligning the strategy and culture for success. Performance improvement, 46(1):21-25, January.

Tromp PJ. 1998. Creating a meeting of minds: A manager's and facilitators guide to effective collaboration. Johannesburg: Knowledge Resources.

Trompenaars F \& Prud'Homme P. 2004. Managing change across corporate cultures. Chichester: Capstone. Weeks RV. 2007. Revelling in the mess of the flat world services economy: A strategic management and organisational culture perspective. Journal of contemporary management, 4:116-137. 
Vandermerwe S. \& Rada J. 1988. Servitization of business: adding value by adding services. European Management Journal, 6(4):314-324.

Weeks J. 2004. Whining Away the Hours. Harvard Business Review, 82(5):20-21, May.

Weeks RV. 2010. The culture and skills challenges associated with servitization: A South African perspective. Journal of contemporary management, 7:1-19.

Weeks RV \& Lessing. 1993. Strategic management: A turbulent environmental perspective. Pinegowrie: NZK

Weeks J. \& Galunic C. 2003. A theory of the cultural evolution of the firm: The intra-organizational ecology of memes. Organization Studies, 24(8):1309-1352

Weick KE \& Sutcliffe KM. 2007. Managing the unexpected: Resilient performance in an age of uncertainty, $2^{\text {nd }}$ edition. San Francisco: John Wiley.

Wikipedia, Paradigm. Available online: http://en.wikipedia.org/wiki/Paradigm [6 February, 2010]

World Economic Forum. 2009. The Global Competitiveness Report 2009-2010. World Economic Forum, Geneva, Switzerland.

Wölfl A. 2005. The services economy in OECD countries. Organisation for Economic Co-Operation and Development (OECD), Statistical analysis of science, technology and industry, working paper 2005/3. Available online: http://www.oecd.org/sti/working-papers [7 February 2010] 